\title{
Reação e resistência de porta-enxertos de tomateiro à murcha de fusário
}

\author{
Reaction and resistance of tomato rootstock to Fusarium wilt
}

\author{
Rafael Ricardo Cantú ${ }^{*}$ José Angelo Rebelo ${ }^{I}$ Paola Mendes Milanesi ${ }^{\text {II }}$ Rumy Goto ${ }^{\text {III }}$
}

\section{- NOTA -}

RESUMO

O objetivo deste trabalho foi verificar a reação de resistência de porta-enxertos e cultivares de tomateiro à raça 3 de F. oxysporum $f$. sp. lycopersici e a comprovação de sua resistência às raças 1 e 2. Os porta-enxertos testados foram: Guardião, Helper-M, Anchor-T, Dr. K, Kagemuscha, Block, Magnet e HeMan, e, como testemunhas, as cultivares 'Kada', 'Santa Clara', 'Gisele', 'BHRS 2,3'. O delineamento experimental utilizado foi o inteiramente casualizado, com parcelas subdivididas e 5 repetições, sendo os porta-enxertos e as cultivares, alocados na parcela principal e as 3 raças de $\mathbf{F}$. oxysporum $f$. sp. lycopersici, nas subparcelas. As plantas foram inoculadas e mantidas em casa de vegetação com temperatura e umidade controladas. Os portaenxertos foram avaliados pela severidade de infecção do fungo no xilema. Todos os porta-enxertos foram resistentes às raças 1 e 2 de Fusarium oxysporum $f$. sp. lycopersici e apenas Guardião e Block foram resistentes à raça 3.

Palavras-chave: Solanum lycopersicon,Fusarium oxysporum $f$. sp. lycopersici, raças, enxertia.

\section{ABSTRACT}

The aim of this research was to verify the reaction of tomato rootstocks to race 3 of $\boldsymbol{F}$. oxysporum $f$. sp. lycopersici and his resistance to races 1 and 2. It was tested the rootstocks: Guardião, Helper-M, Anchor-T, Dr K, Kagemusha, Block, Magnet and He-man and, as a control, the cultivars 'Kada', 'Santa Clara', 'Gisele', 'BHRS 2,3'. The experimental design was a completely randomized type, with split-plots and 5 replicates. The rootstocks and cultivars were allocated in principal plot, and the 3 races of $\boldsymbol{F}$. oxysporum $f$. sp. lycopersici, in the sub-plots. The plants were inoculated and maintained in vegetation house with temperature and humidity controlled. The rootstock was assessed by the severity of disease infection in the xylem. All rootstock were resistant to races 1 and 2 of $\mathbf{F}$. oxysporum $f$. sp. lycopersici and only Guardian and Block were resistant to race 3.

Key words: Solanum lycopersicon, Fusarium oxysporum $f$. sp. lycopersici, races, grafting.

Fusarium oxysporum f. sp. lycopersici é um fungo de solo, causador da murcha de fusário que infecta a maioria das espécies do gênero Solanum, muito embora possa ser patogênico a outros gêneros e espécies (VALE et al., 2004). O patógeno infecta o sistema radicular das plantas, independentemente de ferimentos, e posteriormente o xilema, de modo progressivo até sua totalidade. Em mudas, um dos sintomas mais evidentes é a murcha, seguida por amarelecimento, o que pode provocar a morte da plântula. Ainda, é possível observar no xilema uma coloração marrom intensa, característica da doença (MILLER et al., 2002). A doença pode provocar perdas de até 100\% na lavoura (LOPES et al., 2003).

Atualmente, são conhecidas as raças 1, 2 e 3 de $\mathbf{F}$. oxysporum f. sp. lycopersici, que diferenciamse por sua habilidade de infectar e causar a doença em uma série diferenciadora (REIS et al., 2004). A incidência de raça 3 já foi observada na península de Baja California Sur- México (HOLGUÍN-PEÑA, 2005) e, no Brasil, os primeiros relatos dessa raça do patógeno em tomateiro foram registrados no Espírito

IEmpresa de Pesquisa Agropecuária e Extensão Rural de Santa Catarina (EPAGRI), Rod. Antônio Heil, km 6, nº 6800, 88318-112, Itajaí, SC, Brasil. E-mail: rrcantu@epagri.sc.gov.br.*Autor para correspondência.

IDDepartamento de Solos, Centro de Ciências Rurais (CCR), Universidade Federal de Santa Maria (UFSM), Santa Maria, RS, Brasil.

IIIDepartamento de Produção Vegetal, Faculdade de Ciências Agrárias (FCA), Universidade Estadual Paulista (UNESP), Botucatu,SP, Brasil. Recebido 20.06.13 Aprovado 30.09.13 Devolvido pelo autor 30.04.14 CR-2013-0843.R1 
Santo e no Rio de Janeiro (REIS et al., 2005; REIS et al., 2007). A ocorrência dessa raça também foi registrada em plantios comerciais no Nordeste do país (BARBOZA et al., 2013). Por isso, a utilização de porta-enxertos de tomateiro poderia ser uma alternativa viável para a indução de resistência às raças do patógeno (CANTU et al., 2009). Assim, o objetivo deste trabalho foi verificar a reação de resistência de porta-enxertos às raças 1,2 e 3 de $\boldsymbol{F}$. oxysporum f. sp. lycopersici.

O experimento foi conduzido no Departamento de Produção Vegetal, Setor de Horticultura da FCA/UNESP, Botucatu-SP, nos meses de janeiro a fevereiro de 2006. A pesquisa foi conduzida em um delineamento experimental inteiramente casualizado, com parcelas subdivididas e 5 repetições, sendo os porta-enxertos e as cultivares alocados na parcela principal e as 3 raças de $\boldsymbol{F}$. oxysporum f. sp. lycopersici, nas subparcelas. Cada repetição constituiuse de uma planta por vaso. Os porta-enxertos comerciais estudados foram: Guardião, Helper-M, Anchor-T, Dr. K, Kagemuscha, Block, Magnet e He-Man. Como testemunhas, foram utilizadas as cultivares comerciais 'Santa Clara', resistente à raça 1; Kada, suscetível às raças 1 e 2; Gisele, resistente à raça 2; e BHRS 2,3, resistente às raças 2 e 3.

Os isolados das raças 1,2 e 3 de $\boldsymbol{F}$. oxysporumf. sp. lycopersici foram obtidos de tomateiro com sintomas de murcha, sendo a raça 1 oriunda de lavouras de Botucatu-SP; a raça 2, de lavouras de Paty de Alferes-RJ; e a raça 3, de lavoura de Itaberuna-RJ. As raças, previamente identificadas através de PCR, utilizando-se um conjunto de primers específicos para a diferenciação das raças do patógeno, foram enviadas pela empresa Sakata Seed Sudamerica (São Paulo, Brasil). A multiplicação do inóculo de cada raça foi feita simultaneamente em meio de cultura Batata-Dextrose-Ágar (TUITE, 1969), vertido em placas de Petri. Após a inoculação do meio, as placas foram incubadas a $20^{\circ} \mathrm{C}$ e fotoperíodo de $12 \mathrm{~h}$, durante 10 dias, no laboratório do Departamento de Produção Vegetal, Setor de Defesa Fitossanitária da FCA/UNESP-Botucatu, SP.

A semeadura dos tomateiros foi realizada em bandejas de poliestireno expandido de 128 células, com substrato comercial Plantmax HT. Aos 18 dias após emergência, as mudas foram retiradas das bandejas e tiveram as raízes lavadas e cortadas a $2 \mathrm{~cm}$ do colo da planta. O sistema radicular foi mergulhado em uma suspensão de conídios das raças 1 , 2 e 3 de $\boldsymbol{F}$. oxysporum f. sp. lycopersici, contendo $10^{6}$ conídios $\mathrm{mL}^{-1} /$ suspensão, durante cinco minutos. Após a inoculação, as mudas foram transplantadas para vasos com capacidade para 1L, contendo substrato autoclavado composto por solo argiloso:areia:esterco bovino (1:1:1). Posteriormente, as plantas foram levadas para casa de vegetação, sob temperatura entre 20 e $30^{\circ} \mathrm{C}$ e umidade do ar em torno de $70 \%$, registradas por termohigrógrafo. A irrigação foi feita diariamente através de gotejamento.

Os critérios adotados para avaliação de resistência foram: i) nota 0: plantas sem presença de sintomas nos vasos condutores; ii) nota 1: sintomas logo acima da região cotiledonar; iii) nota 2: sintoma até a $1^{\underline{a}}$ folha; iv) nota 3 : com sintoma até a $2^{\underline{a}}$ ou $3^{\text {a }}$ folhas; v) nota 4: sintomas em mais de três folhas; e vi) nota 5: morte da planta. As plantas com nota 0 foram classificadas como resistentes (R); com notas 1 e 2, moderadamente suscetíveis (MS); e com notas 3, 4 e 5, suscetíveis (S) (REIS et al., 2004). Essa avaliação foi realizada aos 21 dias após a inoculação, examinando-se a área seccionada do caule e dos vasos, expostos por raspagem da epiderme logo acima dos cotilédones.

Todos os porta-enxertos avaliados foram resistentes (R) às raças 1 e 2 de $\boldsymbol{F}$. oxysporum f. sp. lycopersici. A cultivar 'Kada', padrão de suscetibilidade a essas raças, mostrou-se suscetível, como o esperado. Para a cultivar 'Santa Clara', foi confirmada a sua suscetibilidade à raça 2, através da observação de escurecimento nos vasos condutores da planta, como as demais plantas suscetíveis. Os porta-enxertos Block e Guardião foram resistentes (R) à raça 3, sendo os demais suscetíveis (S) a esta raça. A cultivar 'Kada', foi suscetível à raça 3 e a cultivar 'Gisele', que é resistente às raças 1 e 2, foi moderadamente suscetível (MS) à raça 3. Comportamento similar foi observado para a cultivar 'BHRS 2,3', padrão de resistência às raças 2 e 3 , que foi resistente $(\mathrm{R})$ às raças 1 e 2 , porém moderadamente suscetível (MS) à raça 3 (Tabela 1).

A resistência dos porta-enxertos às raças 1 e 2 de $\boldsymbol{F}$. oxysporum f. sp. lycopersici foi confirmada conforme especificado pelas empresas produtoras desses materiais. A constatação da moderada suscetibilidade (MS) da cultivar 'BHRS 2,3' à raça 3 também foi observada por REIS et al. (2004), o que expõe a necessidade de se confirmar a resistência de cultivares de tomateiro, indicados para áreas com presença da raça 3 do patógeno. Adiversidade genética dos fungos é um entrave para o desenvolvimento de cultivares resistentes, visto que muitos fitopatógenos são hábeis na quebra de resistência em um curto espaço de tempo (ZACCARO et al., 2007). 
Tabela 1 - Reação de porta enxertos e cultivares de tomateiro às raças 1, 2 e 3 de Fusarium oxysporum f. sp. lycopersici.

\begin{tabular}{|c|c|c|c|c|c|c|c|c|c|}
\hline \multirow[t]{2}{*}{ Porta-enxertos } & \multicolumn{3}{|c|}{ '----------------Raça 1----------------- - } & \multicolumn{4}{|c|}{ 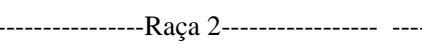 } & \multicolumn{2}{|c|}{----Raça 3------- } \\
\hline & $\mathrm{S}$ & MS & $\mathrm{R}$ & $\mathrm{S}$ & MS & $\mathrm{R}$ & $\mathrm{S}$ & MS & $\mathrm{R}$ \\
\hline Anchor T & & & $\mathrm{x}$ & & & $\mathrm{x}$ & $\mathrm{x}$ & & \\
\hline Guardião & & & $\mathrm{x}$ & & & $\mathrm{x}$ & & & $\mathrm{x}$ \\
\hline Dr. K & & & $\mathrm{x}$ & & & $\mathrm{x}$ & $\mathrm{x}$ & & \\
\hline Kagemusha & & & $\mathrm{x}$ & & & $\mathrm{x}$ & $\mathrm{x}$ & & \\
\hline Helper M & & & $\mathrm{x}$ & & & $\mathrm{x}$ & $\mathrm{x}$ & & \\
\hline He-man & & & $\mathrm{x}$ & & & $\mathrm{x}$ & $\mathrm{x}$ & & \\
\hline Magnet & & & $\mathrm{x}$ & & & $\mathrm{x}$ & $\mathrm{x}$ & & \\
\hline Block & & & $\mathrm{x}$ & & & $\mathrm{x}$ & & & $\mathrm{x}$ \\
\hline \multicolumn{10}{|l|}{ Cultivares } \\
\hline ‘Kada’ & $\mathrm{x}$ & & & $\mathrm{x}$ & & & $\mathrm{x}$ & & \\
\hline 'Gisele' & & & $\mathrm{x}$ & & & $\mathrm{x}$ & & $\mathrm{x}$ & \\
\hline ‘BHRS 2,3’ & & & $\mathrm{x}$ & & & $\mathrm{x}$ & & $\mathrm{x}$ & \\
\hline 'Santa Clara' & & & $\mathrm{x}$ & $\mathrm{x}$ & & & $\mathrm{x}$ & & \\
\hline
\end{tabular}

S: suscetível; MS: moderadamente suscetível; R: resistente.

Fatores ambientais, disponibilidade de cálcio, fertilizantes utilizados e estado nutricional da planta afetam a suscetibilidade do tomateiro a F. oxysporum f. sp. lycopersici (CARVALHO et al., 2004). Por isso, a utilização de porta-enxertos resistentes deve ser combinada com outras práticas culturais, que minimizem o desenvolvimento do fungo no solo e a consequente infecção do tomateiro. Devido à raça 3 de $\boldsymbol{F}$. oxysporum $\mathrm{f}$. sp. lycopersici ser mais restrita ao Sudeste do Brasil, ainda é permitida a utilização de materiais resistentes à murcha de fusário nas demais áreas de cultivo de tomateiro com presença da raça 3 do patógeno (REIS \& BOITEUX, 2007).

De modo geral, os porta-enxertos Guardião, Helper-M, Anchor-T, Dr. K, Kagemuscha, Block, Magnet e He-Man podem ser utilizados em áreas infestadas com $\boldsymbol{F}$. oxysporum $\mathrm{f}$. sp. lycopersici, raças 1 e 2, e somente os porta-enxertos Guardião e Block podem ser utilizados em locais com incidência da raça 3.

\section{AGRADECIMENTOS}

À Empresa de Pesquisa Agropecuária e Extensão Rural de Santa Catarina (EPAGRI) pelo apoio para a condução desta pesquisa, à Fundação de Amparo à Pesquisa do Estado de São Paulo (FAPESP) (suporte financeiro; processo ${ }^{\circ}$ 06/58340-8), à empresa SAKATA que disponibilizou os isolados de $\boldsymbol{F}$. oxysporum f. sp. lycopersici, e aos revisores anônimos pelas importantes sugestões e correções.

\section{REFERÊNCIAS}

BARBOZA, E.A. et al. Identification of Fusarium oxysporum f. sp. lycopersici Race 3 Infecting Tomatoes in Northeast Brazil. Plant Disease, v.97, n.3, p.422, 2013. Disponível em: <http:// apsjournals.apsnet.org/doi/abs/10.1094/PDIS-08-12-0779PDN>. Acesso em: 27 maio 2013. doi: 10.1094/PDIS-08-120779-PDN.

CANTU, R.R et al. Produtividade e crescimento do tomateiro Paron enxertado em diferentes porta enxertos. Revista Agropecuária Catarinense, v.22, n.2, p.67-71, 2009.

CARVALHO, A.O. et al. Colonização de raízes de tomateiro por Fusarium oxysporum f. sp. lycopersici em solução nutritiva com três fontes de nitrogênio. Fitopatologia Brasileira, v.30, p.2632, 2004. Disponível em: <http://www.scielo.br/pdf/fb/v30n1/ a05v30n1.pdf>. Acesso em: 20 maio 2013. doi: 10.1590/S010041582005000100005.

HOLGUÍN-PEÑA, R.J. Fusarium wilt of tomato caused by Fusarium oxysporum f. sp. lycopersici Race 3 in Baja California Sur, Mexico. Plant Disease, v.89, n.12, p.1360, 2005. Disponível em: <http:// apsjournals.apsnet.org/doi/abs/10.1094/PD-89-1360C>. Acesso em: 28 maio, 2013. doi: 10.1094/PD-89-1360C.

LOPES, C.A. et al. Principais doenças do tomate para mesa causadas por fungos, bactérias e vírus. Informe Agropecuário, v.24, n.219, p.66-78, 2003.

MILLER, S.A. et al. Fusarium and Verticillium wilts of tomato, potato, pepper, and eggplant. Ohio: The Ohio State University Extension fact sheet, HYG-3122-96, 1-4, 2002. Disponível em: <http://ohioline.osu.edu/hyg-fact/3000/3122.html>. Acesso em: 25 maio, 2013. 
REIS, A.; BOITEUX, L.S. Ocorrência da raça 3 de Fusarium oxysporum f. sp. lycopersici em lavouras comerciais de tomate para mesa no estado do Rio de Janeiro. Horticultura Brasileira, v.25, p.451-454, 2007. Disponível em: <http://www.scielo.br/ pdf/hb/v25n3/a25v25n3.pdf>. Acesso em: 11 junho, 2013. doi: 10.1590/S0102-05362007000300025

REIS, A. et al. First report of Fusarium oxysporum f. sp. lycopersici race 3 on tomato in Brazil. Fitopatologia Brasileira, v.30, n.4, p.426-428, 2005. Disponível em: <http://www.scielo.br/pdf/fb/ v30n4/a17v30n4.pdf>. Acesso em: 11 junho, 2013. doi: 10.1590/ S0100-41582005000400017.

REIS, A. et al. Ocorrência de Fusarium oxysporum f. sp. lycopersici raça $3 \mathrm{em}$ tomate no Brasil e novas fontes de resistência ao patógeno. Brasília: Embrapa Hortaliças, 2004. 36p. (Boletim de Pesquisa e Desenvolvimento, 02).
TUITE, J. Plant pathotological methods: fungi and bacteria. Minneapolis: Burgess Publishing, 1969. 239p.

VALE, F.X.R. et al. Doenças causadas por fungo em tomate. In: ALVARENGA, M.A.R. (Ed.). Tomate produção em campo, em casa de vegetação e em hidroponia. Lavras: Editora Universitária da UFLA, 2004. p.249-253.

ZACCARO, R.P. et al. Utilização de marcador molecular SCAR na identificação de Fusarium subglutinans, agente causal da malformação da mangueira. Revista Brasileira de Fruticultura, v.29, p.563-570, 2007. Disponível em: <http:// www.scielo.br/scielo.php?script=sci_arttext\&pid=S0100 29452007000300029\&lng=pt\&nrm=iso > . Acesso em: 11 junho, 2013. doi: 10.1590/S0100-29452007000300029. 